\section{O conceito de evento limite: \\ Uma análise de seus diagnósticos}

\section{Pedro Spinola Pereira Caldas $[*, * *]$}

[*] Universidade Federal do Estado do Rio de Janeiro (UNIRIO), Departamento de História, Rio de Janeiro, RJ, Brasil. pedro.caldas@gmail.com / Pesquisador CNPq

[**] O autor é Pesquisador CNPq. Este artigo é resultado de pesquisa financiada com Bolsa em Produtividade de Pesquisa.

ORCID: https://orcid.org/0000-0001-9875-4545
Resumo: No prefácio de um livro fundamental sobre a questão dos limites da representação do Holocausto, Saul Friedländer argumenta que um evento limite pode ser identificado como um evento que testa algumas categorias tradicionais do conhecimento histórico. Logo, torna-se necessário sistematizar quais categorias tradicionais seriam essas. Portanto, escolhi algumas passagens de autores importantes no campo da teoria histórica, tais como Jörn Rüsen, o próprio Saul Friedländer e Dominick LaCapra, nos quais o conceito de evento limite é mencionado, com o objetivo de sugerir o seguinte diagnóstico: (a) de acordo com os três autores, temporalidade, narrativa e imaginação podem ser algumas dessas categorias; (b) todas essas categorias dependem da centralidade do conceito de trauma. Mas eu argumento que, mesmo com sua importância, constatados alguns limites na aplicabilidade do conceito de trauma, podemos pensar em categorias alternativas, tais como a de angústia.

Palavras-chave: Diagnóstico; Evento limite; Temporalidade; Narrativa; Imaginação; Angústia.

\section{Title: The concept of limit event: an analysis of its diagnosis}

Abstract: In the preface of a groundbreaking book on the question of the limits of representation of the Holocaust, Saul Friedländer claims that a limit event can be identified as an event that tests some traditional categories of Historical Knowledge. Therefore, one needs to identify in a more systematic way which traditional categories those could be. Then, I've picked some passages from major authors in the field of Historical Theory, such as Jörn Rüsen, Saul Friedländer himself and Dominick LaCapra, in which the concept of limit event is mentioned, in order to suggest a diagnosis: (a) according to those authors, temporality, narrative and imagination could be some of those categories; (b) all of these three categories can be drawn from the centrality of the concept of trauma. But I claim that, without neglecting its importance, the concept of trauma has also its limits, so one might try to think of alternatives, such as anguish.

Keywords: Diagnosis; Limit event; Temporality; Narrative; Imagination; Anguish. 
urante a preparação deste trabalho, ao consultar novamente as páginas de Os afogados e os sobreviventes, de Primo Levi, reencontrei uma passagem sugestiva:

No Lager, o resfriado e a gripe eram desconhecidos, mas se morria, por vezes subitamente, por males que os médicos não tinham jamais tido a ocasião de estudar. Curavam-se (ou se tornavam assintomáticas) as úlceras gástricas e as doenças mentais, mas todos sofriam de um desconforto incessante, que envenenava o sonho e que não tem nome. Defini-lo "de fundo nervoso" é redutor e ridículo. Talvez fosse justo reconhecer-lhe uma angústia atávica, aquela da qual se sente o eco no versículo do Gênesis: a angústia inscrita em todos do "tòhù vavóhu", do universo deserto e vazio, esmagado sob o espírito de Deus, mas do qual o espírito do ser humano está ausente: ou ainda não nasceu ou já desapareceu. (Levi, [1986]2007, p. 64, trad. minha)

A passagem é um autêntico diagnóstico. Primo Levi fala de doenças convencionais, como gripe e resfriado, úlceras e doenças mentais; fala também de sintomas. Mas aponta um mal, um desconforto, para o qual ele, homem ateu, só consegue encontrar equivalente em um texto religioso. Angústia. E isso me chamou especialmente a atenção, pois, como veremos mais adiante, ao menos quando abordado nas discussões teóricas sobre a Shoah, o conceito prevalente é o de trauma. ${ }^{1}$ Fala-se em experiência traumática, em evento traumático, em representação do trauma, porém, salvo engano, menos em experiência angustiante, em evento angustiante ou em representação da angústia. Ambos os termos podem estar relacionados (cf. Laplanche; Pontalis, 2008, p. 26-27), mas, dadas as ponderações que virão a seguir a respeito do conceito de trauma, pode ser interessante pensar a partir da passagem de Primo Levi, assumindo-a como provocação.

Não foi somente a referência à angústia que me interessou. A indicação feita por Levi de que o desconforto (um tipo de afeto) "não tem nome" (uma carência na cognição) aponta para uma questão tocada justamente quando se fala de trauma ou de representação do Holocausto, a saber, a dissociação entre afeto e cognição:

O extermínio dos judeus na Europa está acessível tanto à representação quanto à interpretação como qualquer outro evento histórico. Mas estamos lidando com um evento que testa nossas categorias tradicionais de ordem conceitual e representacional, um "evento limítrofe" ("event at the limits").

O que faz da "Solução Final" um evento limítrofe é o próprio fato de ser a forma mais radical de genocídio encontrada na história: a tentativa absoluta, deliberada,

' É verdade também que Levi usa o termo “memória traumática” em seu livro (cf. LEVI, [1986]2007, p. 14). 
sistemática, industrialmente organizada e largamente bem-sucedida de exterminar todo um grupo humano no seio da sociedade ocidental no século XX. (Friedländer, 1992, p. 2-3)

Essas palavras podem ser encontradas na introdução escrita por Saul Friedländer para a já consagrada coletânea Probing the Limits of Representation. Assim como os diagnósticos dos médicos, na passagem de Levi, se mostravam ineficazes, as "nossas categorias tradicionais" também teriam problemas ao lidar com todo o processo para o qual os historiadores têm dificuldades até em buscar um nome: Holocausto, Shoah, extermínio, genocídio, "Solução Final”, Auschwitz (como metonímia), só para citar alguns (cf. Sullam Calimani, 2001). Para além da semelhança com o trecho de Primo Levi, a passagem de Friedländer indica-nos um nome para essa situação: evento limite. E daí vem a minha pergunta: como caracterizá-lo? Quais sintomas seriam apresentados por um evento histórico a ponto de ser ele definido como um "limite"? Não mereceria, portanto, a referência de Primo Levi à angústia alguma atenção? De quais critérios dispomos para definir um evento histórico como limítrofe? Afinal: quais seriam essas categorias tradicionais testadas por um evento limite?

Portanto, admitindo que a angústia também pode expressar essa dissociação entre cognição e afeto, também ela não poderia ser um elemento caracterizador de um evento limite? Não tenho como dar resposta agora, sobretudo, porque seria necessário antes fazer um levantamento de como o conceito de trauma serve de fundamento para a indicação de categorias centrais do conhecimento histórico colocadas sob teste. Não tenho pretensão alguma de fazer uma recapitulação exaustiva dessas categorias, sejam as representacionais, sejam as conceituais das quais fala Friedländer, mas isso não pode servir de travo para um passo inicial.

Meu objetivo consiste em fazer um levantamento preliminar. Para desenvolvê-lo, escolhi autores pela sua importância para o campo da pesquisa teórica em história, e que tenham explicitamente usado o termo evento limite, a saber, Jörn Rüsen, Dominick LaCapra e o próprio Saul Friedländer. Minha intenção é, sobretudo, tentar simplesmente escavar alguns pressupostos sobre do que se está falando quando se fala em evento limite. Um diagnóstico dos diagnósticos existentes. Divido o texto em três partes, cada uma dedicada a alguma categoria que pode ser testada a partir desses três autores. Em todos eles, sente-se um peso significativo no conceito de trauma para o estabelecimento de um diagnóstico para evento limite, isto é, para a identificação de três categorias que estariam sendo testadas quando lhes serve de fundamento o conceito de trauma, a saber: temporalidade, narrativa e imaginação. Mediante esse levantamento, talvez consigamos chegar a um entendimento mais preciso da angústia como esse pathos decisivo ao qual se refere Primo Levi. 
Se formos olhar novamente a passagem de Friedländer citada na introdução, veremos que, no primeiro parágrafo, o autor caracteriza o evento limite pelo impacto exercido em todo aquele que pretende conhecê-lo. Já no segundo, descreve as características inerentes do "objeto" causador do evento limite (uma determinada forma de ação humana). Poucos anos depois, Friedländer chegaria a uma denominação mais acurada que poderíamos aplicar a esses dois parágrafos: são dois níveis de problematização, um referente à "natureza histórica do processo moderno" e outro ao "idioma da sua representação" (Friedländer, 1999, p. 22-23). Dito de outra maneira: em um nível encontraríamos a história como experiência ainda não elaborada pelo discurso historiográfico ou qualquer outra forma de representação, e, no outro, precisamente a maneira como os seres humanos procuraram dar sentido à experiência sofrida. Como a sequência dos parágrafos nos leva a crer, seria arbitrário separá-los sem qualquer ponto de tangência.

Uma tentativa de mostrar como os dois níveis de problematização se articulam pode ser encontrada na proposta ideal-típica de Jörn Rüsen, útil por fornecer critérios para um diagnóstico de crises históricas. Em seu texto "Krise, Trauma, Identität", Rüsen apresenta o seguinte diagnóstico para evento limite: "O Holocausto problematiza, e até mesmo bloqueia toda articulação ininterrupta de sentido com o tempo antes e depois dele. Trata-se de uma experiência limite [Grenzerfahrung] da História, que refuta uma integração em um padrão de interpretação da História. Fracassa toda tentativa de aplicar sobre ele uma concepção abrangente de desenvolvimento" (Rüsen, 2002, p. 155, trad. e grifo meus).

Mesmo correndo um risco, gostaria de deixar de lado a possível diferença terminológica entre "experiência" e "evento" na caracterização do que possa ser limítrofe, mas por ora prefiro indicar o quanto a definição de Rüsen reproduz a de Friedländer: o Holocausto é um evento limite por não se deixar explicar plenamente por "concepções abrangentes de desenvolvimento" (sendo a "natureza histórica do processo moderno" uma delas).

Podemos tentar identificar quais seriam essas concepções abrangentes de desenvolvimento. É importante reproduzir aqui o tipo ideal construído por Rüsen: em primeiro lugar, convém lembrar que, para Rüsen, "não haveria consciência histórica se não houvesse crises" (Rüsen, 2002, p. 148), o que justamente reforça a necessidade de estabelecimento de critérios precisos e, portanto, capazes de estabelecer um diagnóstico de uma crise causada por um evento limite. Assim sendo, para Rüsen, teríamos três tipos de crise: a "normal", a "crítica" e a "catastrófica". A primeira "pode ser superada com possibilidades culturais previamente dadas na consciência histórica. A experiência [...] desafiadora é integrada em uma narrativa, no âmbito da qual adquire sentido" (ibidem, p. 153). Um exemplo dado por Rüsen seria a reunificação alemã em 1990, que, dentro de uma perspectiva conservadora, 
significaria uma retomada do caminho do desenvolvimento nacional alemão (cf. ibidem). Já a crise crítica "só pode ser solucionada quando novos elementos são colocados em jogo, e que superem as possibilidades existentes de atribuição de sentido da cultura histórica" (ibidem). Rüsen dá um exemplo na mesma trilha: uma superação crítica da crise seria compreender a reunificação alemã a partir de um paradigma mais inclusivo e menos nacionalista, levando em conta o surgimento da União Europeia e do multiculturalismo resultante dos fluxos migratórios, fatores históricos inexistentes no século XIX e altamente relevantes no fim do século XX (cf. ibidem). Por fim, haveria a crise "catastrófica", que se caracterizaria por "destruir a possibilidade da consciência histórica" (ibidem), pois a assimilação dessa experiência de crise "emudeceria a linguagem do sentido histórico" (ibidem, p. 154), para a qual Rüsen indica três exemplos: o significado da queda do Muro e da Reunificação para os cidadãos da antiga Alemanha Oriental, o Terror jacobino na Revolução Francesa e, por fim, o Holocausto, por ele considerado "paradigmático" (ibidem, p. 170) e também "a experiência mais radical deste tipo de crise catastrófica na história" (ibidem, p. 154).

Assim, a crise catastrófica apresenta o sintoma da experiência traumática: "Trauma é uma crise que destrói os quadros de referência e impede sua renovação em direção a outro" (Rüsen, 2002, p. 152). Se formos usar os termos de Friedländer, a crise normal não testa as categorias (ou os "quadros de referência") existentes; a crise crítica as invalida em seu teste, mas consegue criar novas; já a crise catastrófica invalida o existente e impede a criação de novas. É o que Jacques Derrida expressou em imagem eloquente: o Holocausto é um terremoto que não só destrói vidas humanas, edificações e a natureza, mas também os instrumentos capazes de medi-lo (apud Friedländer, 1999, p.22).

O que está em teste, portanto, na teoria de Rüsen? Quais são os "quadros de referência" destruídos? No mesmo artigo, podemos ver um elenco de mecanismos capazes de amortecer o impacto disruptivo de uma experiência traumática. Embora não busque diretamente indicar quais referências seriam essas, Rüsen apresenta uma lista razoável de mecanismos capazes de apaziguar o impacto de uma experiência limite, tais como: produção de anonimato (mediante o uso de expressões como 'período sombrio' ou 'forças demoníacas'), categorização (por exemplo: o conceito de 'tragédia'), normalização (a referência ao assassinato em massa como algo que ocorre de tempos em tempos), moralização (presente em exortações como 'nunca mais'), estetização (entendido por Rüsen como o acesso aos sentidos mediante, sobretudo, filmes comerciais), teleologização (o horror é meio, parte de um processo que, de alguma forma, compensa as atrocidades), reflexão teórica (na qual o Holocausto se perde no ar da abstração) e especialização (na qual o Holocausto perderia seu impacto em um contexto mais amplo).

Tentando sintetizar um pouco quais elementos do possível "quadro de referências" foram explicitamente diagnosticados como insuficientes: a produção do anonimato, a 
normalização e a compreensão teleológica podem ser vistas como recursos de atribuição de sentido ao processo histórico, isto é, como algo regido ocasionalmente por forças demoníacas, ou como algo dado a recorrências referentes a uma suposta natureza humana ("maldade" etc.) ou como algo que, apesar dos sofrimentos, sempre pode ser visto como um processo de perfectibilidade. Temos também o veto, por parte de Rüsen, de alguns recursos representacionais (narrativas trágicas e visualizações) e de outros, digamos, de ordem metodológica (teorização e especialização). Se formos olhar bem, o que temos aqui não é tanto um quadro explícito de referências, mas um levantamento (importante) de procedimentos naturalizados como meios eficazes de construção de sentido. Funcionam como pressupostos do discurso que dificilmente são explicitados e abertamente problematizados.

Esse levantamento poderia ser reduzido ainda mais: ao identificar o sintoma da crise gerada pelo Holocausto como traumático, Rüsen propõe uma crítica a quadros de referências que tentam assegurar sentido visando a busca da coerência da ordem temporal. A crise não é só do processo em si, mas na nossa capacidade em lidar com ele, pois os acontecimentos característicos desse processo "têm um caráter 'traumático' e desenvolvem uma força destrutiva [...] com esta força, ela [a crise] permanece sendo uma [...] fronteira intransponível para a coerência na ordem temporal da vida humana” (Rüsen, 2002, p. 170).

Em seu lugar, Rüsen propõe um conjunto de estratégias que abandonem a pretensão de coerência de sentido, fazendo da "própria ausência de sentido um elemento constitutivo do sentido histórico” (Rüsen, 2002, p. 178). ${ }^{2}$ Para ele, é fundamental que a representação seja feita a partir de uma determinada posição, a saber: a da traumatização secundária (ibidem, p. 177) a ser incorporada na narrativa histórica, que deveria, segundo Rüsen, enfatizar, por exemplo, a crueza e brutalidade dos fatos no lugar do anonimato, a problematização de categorias anteriormente aplicáveis, a normalização da excepcionalidade ao invés de sua delimitação, a fragilidade interna da moralização como contraponto à edificação, a feiura como alternativa à visibilidade capaz de fazer acessível o horror, a descontinuidade ao invés da teleologia, a articulação entre empiria e reflexão teórica como crítica à abstração, e, por fim, uma história mais integrada como meio para combater os efeitos neutralizadores da especialização (cf. ibidem, p. 178-179).

Reproduzida aqui a teoria das crises proposta por Rüsen, poderíamos afirmar que uma categoria testada, ou um elemento questionável do quadro de referência, talvez pudesse ser a própria ideia de temporalidade.

2 Um bom caso de uma estratégia narrativa que incorpora em si a ausência de sentido poderia ser visto, segundo Shoshana Felman, no documentário Shoah, de Claude Lanzmann, de que servem de exemplo as cenas em que o espectador sabe que a intérprete enfrenta dificuldades em traduzir as conversas entre Lanzmann (o diretor do filme se coloca na frente das câmeras) e os testemunhos entrevistados. Uma lacuna fica dada e explicitada (cf. FELMAN, 1992, p. 210-212). 
Porém, caso levemos em consideração o aparato conceitual que poderia dar conta do fenômeno, esse diagnóstico pode demonstrar alguma imprecisão, pois, se concordarmos com a imagem de que o Holocausto é uma experiência catastrófica porque é um teste para as categorias, por que a própria categoria do trauma não foi, ela também, colocada em questão?

Faço a pergunta por este motivo: sabe-se que o conceito de trauma foi desenvolvido antes da Segunda Guerra Mundial, e o fato de esse conceito ainda ser aplicável para situações após a Guerra não impediria que a crise pudesse ser caracterizada como catastrófica (tal como definida por Rüsen), pois já haveria um conceito disponível, ainda que recente, para nomear a experiência? Fica a questão. Como talvez não seja possível respondê-la cabalmente, vamos a alguns dados: em 1919, Sigmund Freud, em seu texto "Introdução à Psicanálise das neuroses de guerra", já apresenta uma teoria para enfrentar um problema concreto, a saber, como lidar com os problemas sofridos por aqueles que lutaram na Primeira Guerra Mundial? Uma das respostas encontradas naquele breve texto é esta: "nas neuroses traumáticas e de guerra, o Eu do indivíduo se defende de um perigo que o ameaça desde fora, ou que é corporificado numa postura do próprio Eu" (Freud, 2010, p. 387).

As contribuições de Freud se dão em um contexto intelectual bastante preciso, muito bem reconstruído por Ruth Leys, que nos mostra como "o movimento freudiano se beneficiou com a guerra porque, conforme ficaria claro para os médicos, as vítimas adoeciam não por causa de feridas em seu organismo, mas por causas psíquicas" (Leys, 2013, pos. 285-289), de modo que a "psicanálise pareceu ser a única abordagem teórica e terapêutica capaz de interpretare tratar as desordens funcionais associadas aos traumas da guerra moderna" (ibidem).

Para além da historicidade do próprio conceito, ele também já foi aplicado, e de maneira convincente, na historiografia especializada na memória cultural da Primeira Guerra Mundial. Temos, por exemplo, os casos das pesquisas de Jay Winter (2006, p. 52-53), Silvia Correia (2015, p. 138-148)3 e Anton Kaes. Este último, em seu estudo sobre a cultura alemã no imediato pós-Guerra, demonstra como filmes cujos temas não eram a guerra (como Os Nibelungos, Metropolis, O Gabinete do Dr. Caligarie Nosferatu) elaboraram os traumas vivenciados entre 1914 e 1918. Se já vinha sendo pensado no âmbito das ciências psicológicas em geral, o livro de Kaes (2011, pos. 141-151) me parece ser prova convincente de que, uma vez

\footnotetext{
${ }^{3}$ Fazendo referência aos trabalhos pioneiros de Peter Braham, Eric Leed e George Mosse, Silvia Correia percebe, no caso português, uma relação tensa entre a situação de estresse pós-traumático de inválidos de guerra (da Primeira Guerra Mundial, claro está) e construção de identidade nacional portuguesa após o conflito: "O processo de rememoração pública procurou afastar os inválidos do centro do mito da experiência de guerra, uma vez que estes entravam em confronto com o idealismo subjacente ao mito" (CORREIA, 2015, p. 147).

${ }^{4}$ Reproduzo o objetivo de Kaes: "este livro defenderá a ideia de que o cinema de Weimar foi acossado pela memória de uma guerra cujo desfecho traumático jamais foi reconhecido, que dirá aceito [... Muda e escondida, pressuposta e latente, reprimida e negada, a experiência do trauma tornou-se o inconsciente de Weimar" (KAES, 2011, pos. 141-151).
} 
admitido o caráter social do cinema como obra, o trauma já era, ele também, um problema coletivo (ao menos para a sociedade alemã durante a República de Weimar). Portanto, sua caracterização como evento limite precisa de outro diagnóstico para além do traumático. ${ }^{5}$ Afinal, se o terremoto foi capaz de destruir também os aparelhos destinados a medi-lo (para usar a expressão de Jacques Derrida), por que não foi destruído também o conceito de trauma, desenvolvido em um ambiente anterior de crise histórica?

Ainda gostaria de acrescentar algo a partir da leitura de uma entrevista dada por Jean Laplanche (cf. Caruth, 2014, pos. 930-935): o trauma não é fruto de um evento isolado, mas resultado da rememoração de uma experiência anterior reevocada (então reprimida e interiorizada) a partir de um momento posterior, como podemos aprender com a "teoria dos dois momentos". Nesse sentido, como explicar a teoria dos dois momentos para a experiência traumática? Qual teria sido o primeiro momento reprimido, cujo potencial violento teria eclodido com a Segunda Guerra Mundial? Podemos indicar algumas possibilidades, desde a própria Primeira Guerra Mundial, ou, então, toda uma estrutura dialética na qual o Esclarecimento se volta contra si mesmo, tal como mostrado por Adorno e Horkheimer, sobretudo, em sua análise do episódio do canto das Sereias na Odisseia, ou do mito homérico como um todo, no qual também podemos sentir uma cisão entre ação e afeto: "Ulisses descobre nas palavras o que a sociedade burguesa plenamente desenvolvida chama de formalismo: o preço de sua validade permanente é o fato de que elas se distanciam do conteúdo que as preenche em cada caso" (Adorno; Horkheimer, 1985, p. 65). Ou, então, poderíamos ver outra possibilidade na exposição de Raul Hilberg sobre o desenvolvimento das políticas antissemitas na história ocidental, iniciadas com "vocês não podem viver aqui como judeus", passando por "vocês não podem viver aqui" e chegando até "vocês não podem viver" (cf. Hilberg, 1985, p. 7-8). De qualquer forma, se associarmos a crise ocidental causada pelo Holocausto como evento limite à experiência traumática e se entendermos a estrutura da temporalidade do trauma a partir de uma "teoria dos dois momentos", não se estaria aqui notando uma lacuna em um diagnóstico que poderia ser enriquecido caso pensássemos em uma "teoria dos dois momentos"?

Antes de tentar qualquer resposta a essa pergunta, cabe também depurar o que há de válido no conceito de crise catastrófica. Podemos pensar em algumas alternativas: a partir da estrutura temporal inerente à crise catastrófica, temos um passado do qual não se consegue distanciar, e, por essa razão, mostra-se indomável perante os artifícios de procedimentos metodológicos, sempre hábeis em objetivar - e, portanto, controlar - experiências.

${ }^{5}$ Poder-se-ia contrapor que Rüsen indicou como traumática a experiência do Terror jacobino, mas ao classificar - sem especificar as diferenças entre um e outro - como paradigmático o Holocausto, abre-se espaço para uma necessidade maior de caracterização do evento limite. 
Textos talvez não nos faltem caso queiramos, em momento oportuno, elaborar esta ideia de uma certa presença do passado. Penso, por exemplo, no que nos diz Theodor Adorno em "Educação após Auschwitz": "tanto a estrutura básica da sociedade como os seus membros, responsáveis por termos chegado onde estamos, não mudaram nestes vinte e cinco anos" (Adorno [1966]1995, p. 120). E completa com uma frase que encontraríamos formulada de maneira bem parecida por Friedländer na citação que abre este artigo: "milhões de pessoas inocentes foram assassinadas de forma planejada [...] Isto não pode ser minimizado por nenhuma pessoa viva como sendo um fenômeno superficial, como sendo uma aberração no curso da história [...]" (ibidem). Tentando traduzir: o assassinato planejado de inocentes não pode ser reduzido a algum outro fator causal. E há de se ter cuidado: a impossibilidade da redução causal não implica uma excepcionalidade aberrante, justamente porque, semanticamente, a excepcionalidade só faz sentido como contraponto (muitas vezes estatístico) a um padrão e a uma norma. A "teoria dos dois momentos", portanto, pode ganhar esta formulação: o segundo momento existe potencialmente no presente. E essa poderia bem ser uma forma de expressão da crise espocada a partir do evento limite, ou seja, como aquele que impede um distanciamento. ${ }^{6}$ Todavia, com as ressalvas feitas mais acima, será que não poderíamos pensar, além do conceito de temporalidade, outras possibilidades de conceitos tradicionais que podem ser discutidos a partir dessa impossibilidade do distanciamento? ${ }^{7}$ Alguns exemplos: na medida em que não conseguimos nos distanciar, a objetivação torna-se mais complexa, pois a diferença capital entre sujeito e objeto do conhecimento tende a diluir-se. E, como consequência, não ficaria sob teste também a ideia de método, ou seja, o procedimento capaz de nos garantir um conhecimento fiável? E uma terceira possibilidade: com a dificuldade (ou mesmo impossibilidade) do distanciamento, o quanto difícil não se tornaria a criação de um conhecimento perspectivado, ou seja, uma posição construída lentamente pelo pesquisador que lhe daria um foco mais nítido perante o que ele pretende representar. Penso que essas três possibilidades que me ocorreram até o momento talvez deem conta de enfrentar o que Primo Levi nos diz logo no início de Os afogados e os sobreviventes, quando apresenta sua grande motivação para a escrita do livro, "uma pergunta que angustia todos": como saber se os campos de concentração são um fato do passado, ou se já estão

\footnotetext{
${ }^{6}$ Para uma introdução em alto nível à discussão sobre a relação entre distância e conhecimento histórico, cf. Hollander; Paul; Peters, 2011.

Aqui caberia, em momento posterior, um enfrentamento das teses de Mark Salber Philipps sobre o distanciamento. A meu ver, o ponto central está no caráter dialógico sem o qual o distanciamento não se dá, ou seja: o caráter mediado, um ser para si somente ao ser em um outro. Talvez o problema da angústia seja a impossibilidade de, na mediação com o outro, não se conseguir retornar a si, o que nos levaria a uma perturbadora hipótese da inviabilidade da dialética a partir da angústia. Mas esse é um tema para desenvolvimento futuro (cf. PHILIPPS, 2011, p. 11-23).
} 
presentes de novo ou ameaçam retornar? (cf. Levi, [1986]2007, p. 11). Permanece, portanto, aberta a questão da angústia.

II

Reinhard Heydrich tem merecido alguma atenção em narrativas mais recentes sobre o nazismo. Depois de ser um dos protagonistas do fascinante $H H h H$, de Laurent Binet, ganhou algum papel de relevo também na escrita caleidoscópica (cf. Diner, 2010) de Os anos de extermínio, de Saul Friedländer. Pelo menos é o que observou com perspicácia Wulf Kansteiner em sua análise dessa grande obra sobre o extermínio de judeus na Segunda Guerra Mundial: "Heydrich, que morreu em 4 de junho de 1942 depois de ter sido ferido poucos dias antes por comandos tchecos, aparece com proeminência em Os anos de extermínio. Ele aparece em setenta e três páginas do livro" (Kansteiner, 2015, p. 214). Mas não sob a forma analítica e sistemática: "Em algumas destas páginas [...] Heydrich parece renascer dos mortos. Heydrich morre pela primeira vez nas páginas 349 e 350; está vivo de novo na página 352, morto na página 357, vivo nas páginas 362, 367 [...]" (Kansteiner, 2015, p. 214). Não convém reproduzir aqui a reconstrução minuciosa do comentador. O que cito basta para dar um exemplo da impossibilidade de uma representação da continuidade, e, portanto, de uma objetivação do passado pelo distanciamento.

A percepção de Kansteiner fala de uma estratégia narrativa fundamentada em reflexões de caráter mais teórico do próprio Saul Friedländer, mediante as quais o conceito de trauma pode ser visto de maneira um pouco diferente em relação a Rüsen. A seguinte passagem pode nos ajudar na discussão sobre o distanciamento:

A maior dificuldade dos historiadores da Shoah, quando confrontados com os ecos do passado traumático, é a de manter uma medida equilibrada entre a emoção que recorrentemente rompe o 'escudo protetor' e o torpor que protege o mesmo escudo. De fato, o efeito entorpecente ou distanciador do trabalho intelectual sobre a Shoah é inevitável e necessário; e a recorrência do forte impacto emocional é também frequentemente imprevisível e necessária. (Friedländer, 1994, p. 260, grifos meus)

Nessa passagem é mais sinuosa a presença do conceito de trauma, pois os recursos disponíveis não ficam inteiramente invalidados pelo que Rüsen entende ser uma crise catastrófica (e me pergunto, sem saber a resposta, se esta não seria uma maneira de trabalhar a "teoria dos dois momentos"). Esse equilíbrio entre distanciamento e impacto emocional deverá se manter tenso, sem resolução possível, e o evento limite, nesse sentido, não é passível de neutralização normativa. Portanto, o diagnóstico das categorias tradicionais precisa 
dar um passo em outra direção. A criação de efeitos de distanciamento não é discutida nesse artigo por Friedländer, mas importa mais ressaltar que o "escudo protetor" formado por categorias tradicionais testado pelo evento externo não pode ser visto como sintoma de algo ultrapassado, obsoleto e que deve ser substituído por um novo e mais eficaz escudo protetor, como se estivéssemos falando da necessidade de invenção de um capacete de motociclista mais seguro e resistente, e, portanto, capaz de proteger o motorista de acidentes de trânsito potencialmente fatais. O procedimento, para Friedländer, deveria consistir não em uma substituição de paradigma, mas em um trabalho de elaboração (working through) no qual esse equilíbrio imperfeito deveria ser mantido, sem ceder ao que ele chama de "tentação do acabamento [closure]", isto é, da busca evidente de escapar de tudo que permanece "indeterminado, elusivo e opaco" (Friedländer, 1994, p. 261) - o que nos permitiria pensar que, mesmo sem fazer referência a Primo Levi, esse equilíbrio imperfeito poderia ser uma forma de elaborar a angústia.

Partindo de Friedländer, que enfrenta diretamente o problema do distanciamento visto como pressuposto na teoria das crises de Rüsen, podemos pensar, em um primeiro momento, na narrativa como categoria a ser testada, ou por outra: é desafiado o esforço para escapar da indeterminação entre o tique do nascimento e o taque da morte, para usar a formulação clássica de Frank Kermode (cf. Kermode, [1963]2000, p. 57-58), de que serve de exemplo a interpretação de Kansteiner da representação da figura de Reinhard Heydrich, que aparece e reaparece constantemente ao longo do livro. Como exemplo contrário - ou seja, como um caso de "narrativa fechada" - teríamos o que Lawrence Langer identifica no livro de Martin Gilbert sobre o Holocausto, para quem sobreviver e testemunhar já seria uma prova de heroísmo e martírio, uma demonstração de manutenção de dignidade em meio ao sofrimento (cf. Langer, 1991, p. 162-163).

O caso de Heydrich, embora seja apenas um, é significativo do projeto metodológico proposto por Saul Friedländer. Como empregar um método que evite a objetivação, ou, para usarmos os termos do próprio Friedländer, a domesticação do que se estuda? Esse projeto se expressa, sobretudo, no segundo volume de sua obra sobre a Alemanha nazista e os judeus, chamado Os anos de extermínio, cuja estratégia explicativa baseia-se no que ele chama de "uma história integrada" do extermínio. Essa estratégia seria composta pelos seguintes fatores: (l) um raio de tomada de decisões e medidas que fosse além das feitas pelos alemães, mas que também deveria incluir "instituições e reações de autoridades, instituições, e os grupos sociais os mais diversos por toda a Europa ocupada e países satélites controlados pela Alemanha" (Friedländer, 2015, p. 182). (2) Percepções e reações dos judeus, de modo a lhes dar um tratamento qualitativo, de seres humanos capazes de dar sentido ao que viviam e sofriam, ao invés de serem uma massa anônima quantificável (ibidem, p. 182-184). Esses relatos são essenciais, pois "ao contrário de vastos segmentos da sociedade, as vítimas não 
compreendiam o que lhes aguardava no final" (ibidem, p. 183); (3) por fim, a representação da simultaneidade das ações no tempo e no espaço (cf. ibidem, p. 184).

Alon Confino, em sua análise perspicaz de Os anos de extermínio, demonstra como a representação da simultaneidade de ações e sentimentos por toda a Europa ocupada pelo Terceiro Reich rompe com o narrativa causal (cf. Confino, 2010, p. 44). O objetivo de Friedländer seria evitar ao máximo a "domesticação intelectual" da Shoah, adotando o formato narrativo da crônica, sem que as ações fossem determinadas por uma explicação sistemática. Nesse sentido, o evento limite seria aquele capaz de escapar da domesticação propiciada pela reconstrução causal. Ao tentar elaborar o problema do distanciamento pela criação de uma estratégia narrativa, a obra de Friedländer nos permite pensar em outra categoria passível de ser testada, a saber: a de causalidade.

Mas aqui já cabem algumas ponderações: Kansteiner encontra uma explicação para a estratégia narrativa e explicativa de Friedländer ao aproximar Os anos do extermínio de Ulisses, de James Joyce (cf. Kansteiner, 2015, p. 219), na medida em que a unidade cronológica e espacial construída por Joyce é frequentemente quebrada por flashbacks e excessos paratáticos, realizando uma disjunção entre tempo interior e exterior. Uma visão análoga pode ser encontrada na análise feita por Alon Confino da obra magna de Friedländer, com a diferença de que, ao contrário de tomar um romance como Ulisses como referência, o fará com uma obra de historiografia, a saber, O Outono da Idade Média, de Johan Huizinga, que, assim como Friedländer, faz da criação de uma "sensação histórica" um meio de conhecimento intuitivo e sensível do passado tão válido quanto a análise lógico-causal (cf. Confino, 2010, p. 48-50).

Com a reconstrução de uma sensação histórica como algo mais profundo do que um contexto de relações, Confino demonstra como Friedländer, em Os anos de extermínio, não se contenta em estabelecer relações de nexo causal entre os agentes históricos entremeados em sua historiografia integrativa, cabendo, diz Confino, ao leitor preencher com sua imaginação as lacunas deixadas por Friedländer - e assim seria evitada a "tentação do sentido fechado", em que o estilo naturalista da narrativa daria ao leitor a ilusão de estar acompanhando um processo histórico objetivamente dotado de sentido. Um exemplo: após o parágrafo no qual relata o suicídio de Adolf Hitler, em 30 de abril de 1945, Friedländer pula para um parágrafo no qual conta que o cardeal Betram pediu à sua prelazia em Breslau que celebrasse uma missa solene em memória ao Führer. E não se encontrará no texto, nota com precisão Confino, uma conexão causal entre um e outro. Assim, "ele [Friedländer] deixa para o leitor preencher a lacuna e dali extrair o sentido a partir dessa vinheta. Essa narrativa enfraquece as relações causais em favor de sua força descritiva" (Confino, 2010 p. 44-45).

8 Para uma interpretação do conceito de sensação histórica em Huizinga, cf. Ribeiro, 2010 
Sem dúvida, são sofisticadas as análises de Kansteiner e Confino. Ainda assim, talvez hesitasse um pouco se as estratégias identificadas por um e por outro poderiam ajudar a estabelecer um diagnóstico para o evento limite, embora em momento algum fossem esses os seus objetivos. Porém, é válido associar a interpretação das estratégias narrativas de Friedländer (tal como vistas por Kansteiner e Confino ao menos) com o diagnóstico do Holocausto como um evento limite, precisamente porque ele não se deixa "domesticar" inteiramente, servindo de experiência a dificuldade de se distanciar de suas condições de possibilidade (para usar os termos de Adorno). O que me move, na verdade, é perceber o mecanismo da interpretação tanto de Kansteiner como de Confino no que diz respeito ao "idioma da representação", pois, na medida em que é possível reconhecer autores cujas obras referenciais são anteriores ao extermínio - como Ulisses e Outono da Idade Média -, precisamos admitir que, se pegarmos de empréstimo o tipo-ideal de Rüsen para crise, teríamos tido com o extermínio nada além de uma crise normal, uma vez que o passado, mesmo sendo recentíssimo, daria ao historiador recursos para lidar com uma situação crítica posterior. Novamente, o terremoto de que fala Derrida, da mesma forma que não havia destruído o conceito de trauma de Freud, também parece ter preservado o modernismo de Joyce, além da inovação da narrativa historiográfica de Huizinga - que, na verdade, como reconhece Confino, nem tão inovadora foi, pois a apresentação de capítulos em concomitância e sem relação causal aparente remete ao que Jacob Burckhardt fizera em seu clássico Cultura do Renascimento na Itália, ainda em meados do século XIX (cf. Confino, 2010, p. 49).

Não vejo qualquer problema em si nas análises (argutas) de Kansteiner e Confino, mas me pergunto se não seria o caso de nos perguntarmos antes como a narrativa de Friedländer poderia ter ampliado o que fora criado por Joyce ou Huizinga, para ficar nos exemplos destacados pelos comentadores. Não seria essa uma forma de manter a tensão entre o entorpecimento e a abertura emocional, conforme vimos na passagem de Friedländer citada no início desta parte? Infelizmente, não há como fazer aqui uma análise na qual compararíamos Outono da Idade Média e Ulisses com Os anos de extermínio, mas há algo de interessante nas colocações de Kansteiner, e, sobretudo, nas de Confino: ao deslocar para o leitor da obra de Friedländer a responsabilidade da criação de sentido, corre-se o risco de não se interrogar como possivelmente seriam preenchidas as lacunas deixadas pela recusa na explicação causal apaziguadora, pois, afinal, trata-se, sobretudo, de perceber como será feito esse preenchimento, ou, melhor, quais seriam as narrativas predominantes e disponíveis capazes de fornecer recursos para esse preenchimento.

A ponderação me parece necessária: aqui é importante mantermos conosco os comentários prudenciais de Annette Wieviorka ao notar o paradoxo surgido a partir do julgamento de Eichmann em Jerusalém, marca do surgimento da era da "ascensão do testemunho", em que os depoimentos deixam de ter função meramente judicial, documental e 
comprobatória e passam a ter outras dimensões. Em primeiro lugar, uma dimensão ética ao ser dada às vítimas a dignidade de sentirem estar sendo ouvidas; mas também uma inevitável dimensão performática e midiática, que visava, além do papel jurídico necessário, atingir "o coração das pessoas". Uma série incontável de histórias contadas por pessoas de carne e osso e transmitidas pelo mundo tornava visualizável e palpável o seu sofrimento. Mas essa dimensão tem um risco, formulado com precisão por Wieviorka: "O que pode ser dito sobre a publicidade propiciada hoje pela televisão em nossa sociedade do espetáculo, e que pode levar certas testemunhas a ir além dos limites de seu testemunho, moldando-o conforme ao que eles imaginam o que o público quer?" (Wieviorka, 2006, p. 73, trad. minha).

Embora Wieviorka refira-se à linguagem do testemunho e não a um imaginário de cultura de massa, não seria demasiado idealista imaginar o quão aberto estaria o leitor para estratégias narrativas menos convencionais? ${ }^{9}$ Assim, não se estaria correndo o risco de delegar ao leitor a função evitada pelo historiador e/ou testemunho, ou seja, a de dar um sentido arredondado à experiência limítrofe? Evidentemente, nada disso deve inibir o testemunho, mas sim incentivar o trabalho crítico perante narrativas com grande capacidade de difusão. Mas, com isso, entramos em outro nível da discussão. Podemos admitir, portanto, o evento limite como aquele capaz de criticar a função domesticadora de determinados tipos de narrativa, mas a domesticação causada pela reconstrução causal não estaria potencialmente presente só nas técnicas da escrita, e sim em sua circulação e recepção.

A domesticação poderia estar, a meu ver, na domesticação da angústia. É o que aparece novamente em Os afogados e os sobreviventes, quando Levi marca claramente o contraste entre um tipo habitual de recepção de histórias de sobrevivência e os de relatos de testemunhos de campos de concentração. De um lado, "existe um quadro estereotipado, proposto infinitas vezes, consagrado pela literatura e pela poesia, registrado no cinema: ao fim da tormenta, quando surge "a bonança após a tempestade", todo coração se alegra” (Levi, [1986]2007, p. 52); ao que Levi pondera: "a julgar pelas narrativas feitas por muitos sobreviventes e pelas minhas próprias lembranças [...] sair do sofrimento foi um deleite só para alguns poucos afortunados, ou só por alguns instantes, ou para almas muito simplórias; quase sempre coincidiu com uma fase de angústia" (Levi, [1986]2007, p. 52, grifo meu). O ponto é: ao preencher lacunas de sentido, o leitor a faria com suas angústias, ou antes as lacunas dos textos nos abririam para as angústias de sua circunstância histórica? Novamente não tenho respostas. Portanto, proponho seguir com uma reflexão com esta pergunta: qual o impacto

${ }^{9}$ A meu ver, é esse o risco da proposta de Hayden White em seu artigo sobre o evento modernista. Imaginar o leitor contemporâneo, envolvido pela indústria cultural, em condições de ver em narrativas sobre o Holocausto as sutilezas e inovações dos romances de Virginia Woolf é bastante utópico, uma demanda que precisaria estar consciente de sua normatividade prescritiva (cf. WHITE, 1999, p. 76). 
exercido sobre as narrativas do evento limite, sejam elas historiográficas, testemunhais, ficcionais, filosóficas ou de qualquer outro gênero?

III

Hurbinek era um nada, um filho da morte, um filho de Auschwitz. Parecia ter em torno de três anos, e ninguém sabia dele, que não sabia falar e não tinha nome. Hurbinek foi um nome que lhe demos [...] Estava paralisado dos rins para baixo e tinha as pernas atrofiadas, finas como gravetos, mas seus olhos, perdidos no rosto triangular e desfigurado, saltavam terrivelmente vivos, plenos de desejo, de asserção, de vontade de sair das amarras do mutismo. A palavra que lhe faltava, que ninguém cuidou de lhe ensinar, a necessidade da palavra comprimia seu olhar com urgência explosiva: era ao mesmo tempo um olhar selvagem e humano [...] que nenhum de nós sabia como aguentar, de tal forma era carregado de força e de sofrimento. (Levi, [1963]1997, p. 22, trad. minha)

Passagem longa, da qual poderíamos extrair algumas possibilidades de desenvolvimento de nosso argumento. É um trecho que remete ao menino Hurbinek, uma das figuras mais marcantes da literatura de testemunho e que é apresentada no segundo capítulo do segundo livro de Primo Levi, A Trégua, publicado em 1963. Por que nos toca a passagem? Indicaria aqui algumas possibilidades: Hurbinek é "o filho da morte", e encontrá-lo é encontrá-la, e, como a morte tem um claro sentido de "fechamento", Hurbinek se torna uma ligação com o que dizíamos sobre a narrativa como categoria tradicional. Outra possibilidade: Levi se lembra da força explosiva dos olhos de Hurbinek como um espelho quase insuportável. Uma terceira: Hurbinek é, ele mesmo, uma figura limítrofe, pois morre "livre, mas não redimido" em março de 1945. Morre depois da libertação do campo, ou seja, livre do domínio da SS, mas ainda no território do campo. Certamente não é coincidência que o primeiro capítulo de A Trégua chame-se "degelo", ou seja, um momento em que se deixará a frieza, entendida aqui como anulação de toda e qualquer possibilidade de sentir. Inclusive as dores mais reprimidas. Hurbinek é um evento limite, pois parece demarcar um lugar de encontro, uma fronteira, assim como linhas apontam limites entre territórios. Ele é o encontro entre um sobrevivente e um morto (na lembrança da força explosiva do seu olhar), e também entre um período onde se está livre, mas não se está redimido. ${ }^{10}$ E esse encontro servirá de impulso

10 Todavia, para Giorgio Agamben, Hurbinek será o lugar de outro tipo de encontro: "o encontro de duas impossibilidades de testemunhar, que a língua [...] deve ceder lugar a uma não língua, mostrar a impossibilidade de testemunhar" (AGAM- 
para Levi escrever A Trégua: "ele [Hurbinek] testemunha através de minhas palavras" (Levi, [1963]1997, p. 52). Não pretendo discutir aqui como Hurbinek testemunha através de Primo Levi, mas o que pode acontecer conosco em encontros dos quais não conseguimos escapar facilmente. E agora algumas reflexões de Dominick LaCapra poderão ser úteis.

Em artigo integrante de uma coletânea publicada uma década após Probing the limits of representation (para a qual contribuiu), LaCapra escreve:

Toquei na desconcertante questão de como representar e articular eventos limite ou transgressivos associados a experiências traumáticas como o Holocausto (só recentemente se formulou explicitamente o problema da relação entre evento limite e trauma). ${ }^{11}$ Deixe-me inserir aqui que se pode inicialmente definir um evento limite como um evento que ultrapassa a capacidade da imaginação em concebê-lo ou antecipá-lo. Antes que ocorresse, ele não era - e talvez não fosse possível ser - antecipável ou imaginável [...] No mínimo havia uma resistência extrema para vislumbrar sua possibilidade. Logo um tal evento (ou série de eventos) deve ser, em certo sentido, traumático ou traumatizante, e o que requer uma explicação especial é a não traumatização daquele que o experimentou. Mesmo após sua ocorrência, um tal evento ainda pode testar ou possivelmente exceder a imaginação, incluindo a imaginação daqueles que não o experimentaram (aqueles que não estavam lá). (LaCapra, 2004, p. 132-133, trad. e grifos meus)

A propósito dessa passagem, algumas observações. A primeira delas seria esta: LaCapra associa diretamente o evento limite à experiência traumática e também sublinha a dificuldade de representá-lo, mas com duas características importantes. Basta ver a definição dada por LaCapra para o conceito de trauma em outro artigo: "O trauma é uma experiência devastadora que distorce a memória em seu 'sentido ordinário' e a torna particularmente vulnerável e falível ao retratar eventos" (LaCapra, 2009, p. 61). Se olharmos a definição grifada na passagem na qual define evento limite, vemos que, fora a caracterização dos sintomas comportamentais, ambas se aproximam de maneira evidente no que diz respeito à dificuldade de internalizar ou integrar uma experiência sofrida na memória expressa mediante uma narrativa, algo já teorizado por Rüsen e também desenvolvido por Friedländer. A segunda observação toca em um ponto importante da definição de LaCapra sobre evento limite, mais precisamente na sua caracterização a partir de uma carência na imaginação (de quem tenta lhe dar sentido mas não o viveu), e na carência de uma imaginação antecipatória

BEN, 2008, p. 48). Para uma crítica convincente dos argumentos de Agamben, ver o ensaio "Siting Agamben: Approaching Limit Events", de Dominick LaCapra (LaCAPRA, 2004)

"Infelizmente, LaCapra, cujas notas de rodapé são conhecidas pela abundante generosidade de referências bibliográficas, não cita autores que tenham feito essa aproximação. 
(de quem o viveu, dando-lhe ou não sentido posteriormente). O evento limite, portanto, adquire outra qualidade a propósito de sua temporalidade: ele sempre escapa às previsões, expectativas, temores e angústias de quem o viveria. Nesse sentido, o evento limite é efetivamente traumático na medida em que o "escudo protetor" revelar-se-ia demasiado frágil para a proteção dos estímulos externos, e, assim, não afeta somente quem viveu e sofreu diretamente o evento limite, mas também quem, de alguma maneira, se sente afetado por ele, inclusive na dimensão da chamada "pós-memória". ${ }^{12} \mathrm{O}$ evento limite, portanto, adquire sua potência disruptiva ao expor uma dupla precariedade: a do imaginário e/ou das previsões existentes em um momento histórico anterior ao seu acontecimento e também a do aparato conceitual e representacional posterior ao seu surgimento. É difícil elaborar hoje o que, no passado, foi (quase) impossível ser previsto. E aqui poderíamos aplicar para LaCapra as palavras de Friedländer: o evento limite como "teste de nossas categorias", pois quem o estuda precisa ser radicalmente afetado pela insuficiência da imaginação e fragilidade do escudo protetor das vítimas.

Em outro artigo, LaCapra reformula a relação delicada entre o reconhecimento da fragilidade do outro com uma identificação vicária criada por quem sobre ele se debruça: "O problema [...] consiste em como reconhecer a própria vulnerabilidade ou angústia constitutiva, relacionadas às dimensões estruturais ou trans-históricas do trauma, sem historicizar, localizar e inserir nele formas equivocadas de projetar a própria causa nos outros, transformados então em bodes expiatórios" (LaCapra, 2009, p. 193, trad. minha).

LaCapra expressa com precisão um problema: reconhecer a própria vulnerabilidade e - o que é principal - a angústia constitutiva, evitando, porém, a projeção de si nos outros. Afinal, o que acontece na e com nossa imaginação quando entramos em contato com a carência de imaginação de outros seres humanos no passado? Seria o mesmo efeito do olhar de Hurbinek? Pelo que pude compreender de alguns dos ensaios de LaCapra, podemos colocar aqui, junto ao conceito de imaginação, uma terceira das "nossas categorias tradicionais": empatia.

A Empatia é especialmente problemática no caso de eventos traumáticos e na relação de algozes e vítimas com eles. A empatia é muito frequentemente confundida com identificação, especialmente com a vítima, e essa confusão leva à idealização ou mesmo sacralização da vítima [...] A empatia é, penso eu, uma experiência virtual mas não vicária, na qual o/a historiador/a se põe no lugar do outro sem tomar o lugar do outro

12 “Pós-memória é a memória adquirida por aqueles que não experienciaram diretamente um evento como o Holocausto ou a escravidão, e a transmissão intergeracional do trauma se refere ao modo como aqueles que não vivenciaram o evento podem, ainda assim, experimentar e manifestar seus sintomas pós-traumáticos, algo especialmente proeminente nos filhos ou pessoas próximas a sobreviventes ou, às vezes, de algozes" (LaCAPRA, 2004, p.108). 
ou se tornar um substituto ou um delegado do outro que estaria autorizado a falar na voz do outro. A empatia envolve uma resposta afetiva ao outro, e a resposta afetiva interage com a diferença tanto quanto com a distância crítica e análise na historiografia. (LaCapra, 2004, p. 65, trad. e grifo meus)

A empatia, em seu sentido convencional, aparece, nas palavras de LaCapra, como um pressuposto necessário de um determinado tipo de compreensão, a saber, aquela que conhece na medida de sua capacidade de reconstruir a intenção (quando se age) e/ou a condição (quando se sofre) alheias. Claro que não se deve discutir a necessidade da compaixão com as vítimas dos horrores do campo de concentração. ${ }^{13}$ LaCapra não defende a frieza da objetividade. Antes pelo contrário: sabendo ser impossível se colocar no lugar do outro, estamos respeitando-o profundamente.

Em outro momento, LaCapra definirá de maneira mais precisa o que seria uma possibilidade mais interessante de empatia, por ele definida como desestabilização empática (empathic unsettlement): "uma resposta empática exige o reconhecimento do outro como outro, e mais do que meros objetos de pesquisa incapazes de questionar a própria posição em questão [...] a empatia desejável envolve, eu sugiro, uma identificação que não seja autossuficiente, projetiva ou incorporadora, mas que pode ser definida como uma empatia desestabilizadora" (LaCapra, 2004, p. 135, trad. minha).

Todavia, ainda fica a pergunta: o que é desestabilizado nessa relação empática? É necessário um evento limite para tal, ou é da estrutura do próprio conhecimento a produção dessa desestabilização? Como a "própria posição" é colocada em questão? Isso, a meu ver, requer novamente mais algumas ponderações. Qual será a diferença entre uma posição colocada em questão - nos termos formulados por LaCapra - e a própria estrutura do pensamento, tal como podemos ver, por exemplo, na formulação de Arthur Danto, que mostra como, ao pensar um objeto, o pensamento sempre precisa se pensar? (cf. Danto, 2005, p. 98-99). Ao estabelecer um diagnóstico sobre um objeto, o pensamento também não estaria fazendo um diagnóstico sobre si mesmo?

Não é tão complexo criticar a ideia de empatia como sinônimo de identificação plena com o objeto. Johann Gustav Droysen já o fizera em 1857, ao mostrar os limites da interpretação psicológica (cf. Droysen, [1857]1977, p. 189-190). O que está em jogo, a meu ver, é mais do que uma suposta crítica de uma ideia de interpretação ligada a uma hermenêutica capaz de reconstruir intenções, mas algo talvez mais delicado. Estamos falando aqui da posição de um sujeito e do que dele é feito a partir desse posicionamento. Penso em outra

${ }^{13}$ Um exemplo de identificação vicária e projetiva seria, segundo LaCapra, a análise que Giorgio Agamben faz da obra de Primo Levi, que seria tratado pelo filósofo italiano como uma testemunha perfeita, na medida em que testemunhara a impossibilidade de testemunhar (cf. LaCAPRA, 2004, p. 160-161). 
possibilidade: LaCapra fala de fragilidade e angústia constitutivas, e, ao fazê-lo, aponta para uma dimensão interessante.

Podemos entender a empatia inerente ao conhecimento histórico como o reconhecimento da natureza eminentemente contingencial da ação humana. Arrisco esboçar a perspectiva histórica empática desta forma: em meio a um conjunto de ações possíveis (e isso o olhar histórico pode reconstruir), uma delas tornou-se efetiva, ou seja, foi determinante para a sequência do processo histórico. Portanto, compreender empaticamente significa reconstruir o cenário com as opções conscientemente disponíveis para os viventes em um contexto específico, e sua fragilidade estava em, a despeito de suas intenções e planos, não terem como saber quais os efeitos de suas decisões intencional e conscientemente tomadas. O ponto é: como seria uma empatia desestabilizadora neste caso? No caso das vítimas: a radical ausência de opções? O reconhecimento de que seu sofrimento não pode ser compreendido com o pressuposto de que seres humanos têm escolhas? ${ }^{14}$ Quando falamos da dupla carência de imaginação, não estaríamos falando tanto da impossibilidade de seres humanos no passado em imaginarem o que lhes aguardava, como também da impossibilidade de concepção de cenários alternativos para o futuro (uma obra de imaginação) não ser uma carta que tinham à disposição? ${ }^{15}$

O que fazer, então? Não deixa de ser irônico que LaCapra tenha deixado uma pista preciosa em uma modesta nota de rodapé, na qual podemos encontrar uma maneira de identificar outra característica no evento limite. Na nota, LaCapra escreve: "O que é experimentado como traumático é talvez tipicamente entendido naquilo que não se encaixa em um contexto real ou imaginado [...] Freud se refere aqui à ausência da Angstbereitschaft - a prontidão para sentir angústia" (LaCapra, 2004, p. 45, trad. minha). E isso me parece ser o propósito do alerta feito por Primo Levi no final de Os afogados e os sobreviventes, escrito na década de 1980, em um contexto de Guerra Fria, ditaduras latino-americanas e negacionismo historiográfico:

O quão seguros estamos nós, seres humanos do fim do século e do milênio, e, mais particularmente, nós europeus? [...] Os medos de hoje são menos fundamentados que aqueles de outrora? Somos cegos para o futuro, não menos que nossos pais. Suíços e suecos têm refúgios antinucleares, mas que coisa encontrarão quando saírem deles?

\footnotetext{
${ }^{14}$ Com a sensibilidade e inteligência que atravessam todo o seu livro, Lawerence Langer nos mostra como uma característica das ações e memórias dos sobreviventes dos campos é a consciência da ausência de opções. Suas ações dificilmente se deixam reconstruir mediante a ideia de "escolha", ou seja, de uma conexão possível entre agência e destino, possivel a partir da possibilidade de que alguma decisão intencional tenha alguma possibilidade de controle sobre o curso dos eventos (cf. LANGER, 1991, p. 172-179).

${ }^{15}$ A cuidadosa análise de Primo Levi dos Sonderkommando, feita no clássico capítulo sobre a zona cinza em Os afogados e os sobreviventes (LEVI, [1986]2007), parece nos indicar esse rumo.
} 
[...] Obter um passaporte e vistos de entrada é muito mais fácil do que então: por que não partimos, por que não deixamos o nosso país, por que não fugimos "antes que seja tarde"? (Levi, [1986]2007, p. 131, trad. minha)

Embora angustiantes, talvez as palavras de Levi não fossem possíveis na década de 1930. Mas também para isso seria necessário investigar mais. Ainda assim, parece-me que a angústia serve como pathos capaz de elaborar e pensar o limite de categorias como distanciamento, causalidade e empatia.

\section{Referências}

ADORNO, Theodor. Educação após Auschwitz. [1966]. In: ADORNO, Theodor. Educação e emancipação. Rio de Janeiro: Paz e Terra, 1995.

ADORNO, Theodor; HORKHEIMER, Max. Dialética do esclarecimento. [1944/1969]. Rio de Janeiro: Jorge Zahar, 1985.

AGAMBEN, Giorgio. O que resta de Auschwitz: o arquivo e a testemunha. São Paulo: Boitempo, 2008.

CARUTH, Cathy. Listening to Trauma: Conversations with Leaders in the Theory and Treatment of Catastrophic Experience. Baltimore, MD: The Johns Hopkins University Press, 2014.

CONFINO, Alon. Narrative Form and Historical Sensation: On Saul Friedländer The Years of Extermination. In: BETTS, Paul; WIESE, Christian. Years of Persecution, Years of Extermination: Saul Friedländer and the Future of Holocaust Studies. London: Continuum, 2010.

CORREIA, Silvia. Entre heróis e mortos: políticas da memória da I Guerra Mundial em Portugal (19181933). Rio de Janeiro: Faperj: 7Letras, 2015.

DANTO, Arthur. Transfigurações do lugar comum. São Paulo: Cosac Naify, 2005.

DINER, Dan. Kaleidoscopic Writing: On Saul Friedländer's The Years of Extermination: Nazi Germany and the Jews, 1939-1945. In: BETTS, Paul; WIESE, Christian. Years of Persecution, Years of Extermination: Saul Friedländer and the Future of Holocaust Studies. London: Continuum, 2010.

DROYSEN, Johann Gustav. Historik. [1857]. Stuttgart: Fromann-Holzboog, 1977.

FELMAN, Shoshana. The Return of the Voice: Claude Lanzmann's Shoah. In: FELMAN, Shoshana; LAUB, Dori. Testimony: Crises of Witnessing in Literature, Psychoanalysis and History. London: Routledge, 1992.

HOLLANDER, Jap den; PAUL, Herman; PETERS, Rik. Introduction: The Metaphor of Historical Distance. History \& Theory, Theme Issue 50, Dec. 2011.

FREUD, Sigmund. Além do princípio do prazer. In: FREUD, Sigmund. Obras completas. Vol. 14 [19171920]. Tradução de Paulo César de Souza. São Paulo: Companhia das Letras, 2010.

FRIEDLÄNDER, Saul. Auseinandersetzung mit der Shoah: Einige Überlegungen zum Thema Erinnerung und Geschichte. In: KÜTTLER, Wolfgang; RÜSEN, Jörn; SCHULIN, Ernst (orgs.). Geschichtsdiskurs Band 5: Globale Konflikte, Erinnerungsarbeit und Neuorientierungen seit 1945. Frankfurt am Main: Fischer, 1999.

FRIEDLÄNDER, Saul. An Integrated History of the Holocaust: Some Methodological Challenges. In: STONE, Dan (org.). The Holocaust e Historical Methodology. New York: Berghahn, 2015.

FRIEDLÄNDER, Saul. Introduction. In: FRIEDLÄNDER, Saul (org.). Probing the Limits of Representation: Nazism and the "Final Solution". Cambridge, MA: Harvard University Press, 1992. 
FRIEDLÄNDER, Saul. Trauma, Memory and Transference. In: HARTMAN, Geoffrey H. (org.). Holocaust Remembrance: The Shapes of Memory. Oxford: Blackwell, 1994.

HILBERG, Raul. The Destruction of the European Jews. Student Edition. New York: Holmes \& Meier, 1985.

KAES, Anton. Shell Shock Cinema: Weimar Culture and the Wounds of War. Princeton, NJ: Princeton University Press, 2011.

KANSTEINER, Wulf. Modernist Holocaust Historiography: A Dialogue between Saul Friedländer and Hayden White. In: STONE, Dan (org.). The Holocaust \& Historical Methodology. New York: Berghahn, 2015.

KERMODE, Frank. The Sense of an Ending. [1963]. Oxford: Oxford University Press, 2000.

LaCAPRA, Dominick. History and its Limits: Human, Animal, Violence. Ithaca, NY: Cornell University Press, 2009.

LaCAPRA, Dominick. History in Transit: Experience, Identity, Critical Theory. Ithaca, NY: Cornell University Press, 2004.

LANGER, Lawrence. Holocaust Testimonies: The Ruins of Memory. New Haven, CT: Yale University Press, 1991

LAPLANCHE, Jean; PONTALIS, Jean-Bertrand. Vocabulário da Psicanálise. São Paulo: Martins Fontes, 2008.
LEVI, Primo. La Tregua. [1963]. Torino: Einaudi, 1997. LEVI, Primo. I Sommersie I Salvati. [1986]. Torino: Einaudi, 2007.

LEYS, Ruth. Trauma: A Genealogy. Chicago, IL: The University of Chicago Press, 2013. (edição eletrônica).

PHILIPPS, Mark Salber. Rethinking Historical Distance. History and Theory, Theme Issue 50, Dec. 2011.

RIBEIRO, Naiara dos Santos Damas. A morfologia histórica de Johan Huizinga e o caráter pragmático do passado. História da Historiografia, n. 4, mar. 2010.

RÜSEN, Jörn. Krise, Trauma, Identität. In: RÜSEN, Jörn. Zerbrechende Zeit: Über den Sinn der Geschichte. Köln: Böhlau, 2002.

SULLAM CALLIMANI, Anna Vera. I nomi dello sterminio. Torino: Einaudi, 2001.

WHITE, Hayden. The Modernist Event. In: WHITE, Hayden. Figural Realism: Studies in the Mimesis Effect. Baltimore, MD: The Johns Hopkins University Press, 1999.

WIEVIORKA, Annette. The Era of the Witness. Translation by Jared Stark. Ithaca, NY: Cornell University Press, 2006.

WINTER, Jay. Remembering War. New Haven, CT: Yale University Press, 2006. 